\title{
TRANSIENT STABILITY ANALYSIS ON A MULTI-MACHINE SYSTEM IN PSAT
}

\author{
Gamit Melvin Girishbhai ${ }^{1}$, Jigar S. Sarda ${ }^{2}$ \\ ${ }^{1}$ C.S. Patel Institute of Technology, Charotar University of Science and Technology, Anand, India \\ ${ }^{2}$ C.S. Patel Institute of Technology, Charotar University of Science and Technology, Anand, India
}

\begin{abstract}
Modern power system are subject to large disturbances such as three phase short circuit faults. When a fault occurs on a system the generators rotor angle becomes unstable and thus it losses synchronism with the system and it becomes unstable. Thus transient stability analysis can be performed on a system in order to understand the generators performance when subjected to a short circuit fault. When the system is subjected to a fault the generator experiences transient oscillations in rotor speed and angle which can be effectively suppressed with the incorporation of Automatic Voltage Regulator (AVR) and Power System Stabilizer (PSS). The simulations have been performed using the MATLAB/PSAT software.
\end{abstract}

Keywords-Transient stability, Three phase fault Faults, AVR, PSS.

$* * *$

\section{INTRODUCTION}

Power system stability has been a very important problem for secure power system operation since 1920s [1-2]. Many major blackouts caused by power system instability have stressed the importance of this phenomenon [3]. Power system stability is defined as the property of a power system that enables it to remain in a state of equilibrium after being subjected to a disturbance [4-5].

Power system stability is mainly categorized as angle stability and voltage stability. Angle stability is the ability of the power system to maintain synchronism and torque balance of synchronous machines. It is further classified as small-signal stability and transient stability. Voltage stability is defined as the ability of the power system to maintain steady state acceptance voltage and reactive power balance. It is further divided as large disturbance voltage stability and small disturbance voltage stability [6].

Transient stability analysis in power system is concerned with the power systems ability to remain synchronously stable following a server disturbance [6-7]. This paper explains the transient stability analysis problems. Here two area system is used as a test system and transient stability analysis has been performed by simulating a three phase fault on the bus. The simulations have been performed using MATLAB/PSAT toolbox [8]. When a three phase fault is simulated on the test system, the system becomes unstable. Thus AVR and PSS are connected to the synchronous generator for decreasing the inter area oscillations making the system stable [9].

The paper is organized in six chapters. Chapter 2 explains the transient stability in detail, chapter 3 discusses the AVR and PSS used for simulation, chapter 4 contains the test system, chapter 5 contains the simulation results and chapter 6 contains the conclusion.

\section{TRANSIENT STABILITY}

Transient stability is the ability of the power system to maintain synchronism when subjected to a severe transient disturbance such as a fault on transmission facilities, loss of generation, or loss of a large load. The system when subjected to such disturbances can affect the generator rotor angles, power flows, bus voltages and other system variables.

Fig 1 shows a single machine infinite bus system, where the generator is represented by the classical model and the speed governor effects are neglected. Fig 2 represents the equivalent circuit of single machine infinite bus system.

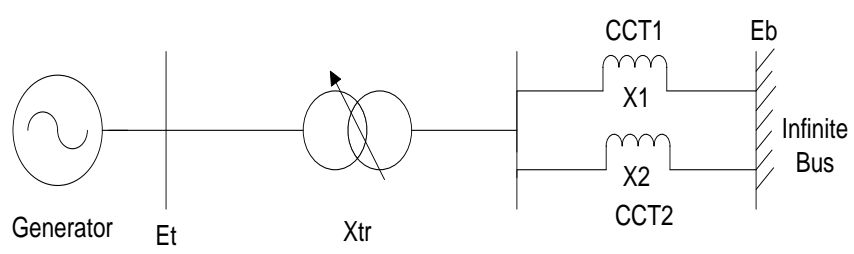

Fig 1: Single-machine infinite bus system

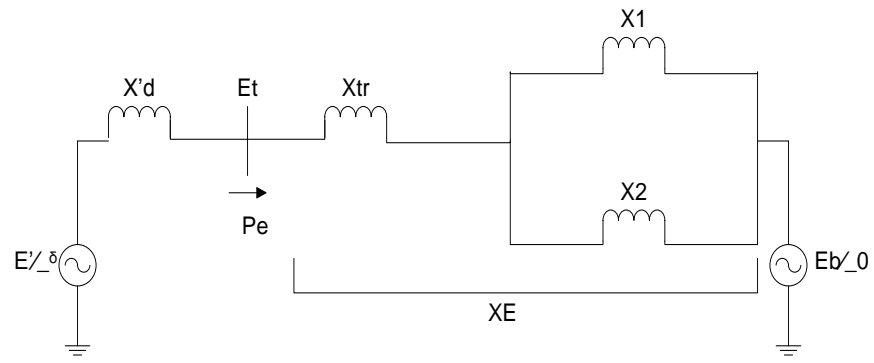

Fig 2: Equivalent circuit 


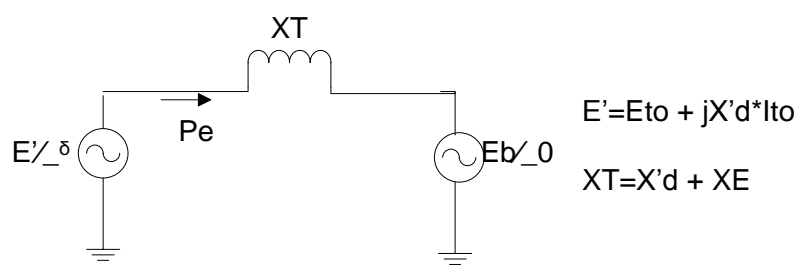

Fig 3: Reduced equivalent circuit

The voltage behind the transient reactance $\left(X_{d}^{\prime}\right)$ is denoted by $E^{\prime}$. The rotor angle $\delta$ represents the angle by which $E^{\prime}$ leads $E_{b}$. When the system is subjected to a disturbance, the magnitude of $E^{\prime}$ remains constant at its pre-disturbance value and $\delta$ changes as the generator rotor speed deviates from synchronous speed $\omega_{0}$.

Fig 3 is the reduced equivalent circuit of the single machine infinite bus system.

The generators electrical power output is

$P_{e}=\frac{E^{\prime} E_{b}}{X_{T}} \sin \delta=P_{\max } \sin \delta$

Where $P_{\max }=\frac{E^{\prime} E_{b}}{X_{T}}$

Since the stator resistance is neglected, $P_{e}$ represents the airgap power as well as the terminal power.

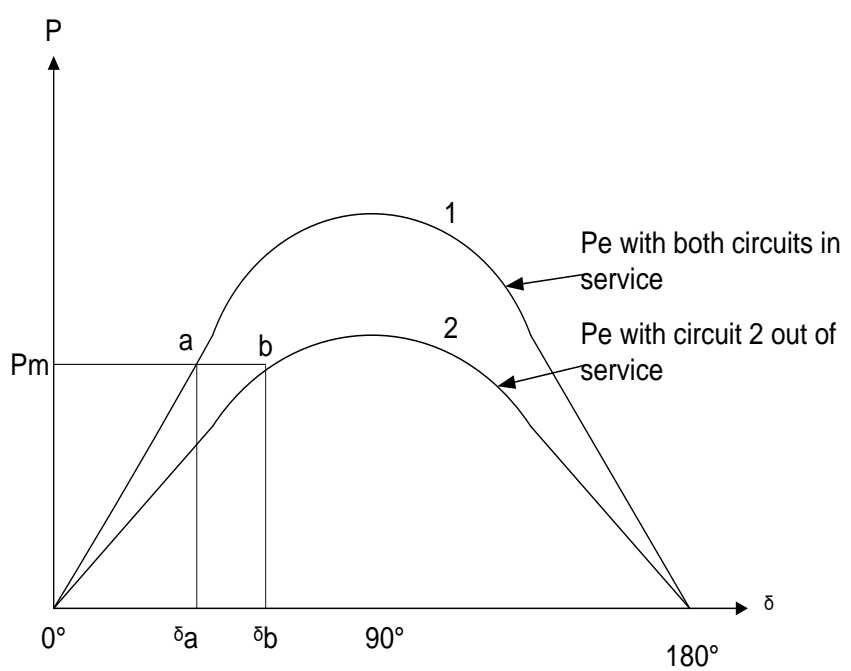

Fig 4: Power-angle relationship

Fig 4 represents the power-angle relationship. There are two curves in fig 4; curve 1 and curve 2. Curve 1 represents the power-angle relationship when both circuits are in service. In this situation when the mechanical input power is $P_{m}$, the steady state electrical power output $P_{e}$ is equal to $P_{m}$ and the operating condition is represented by point a on the curve and $\delta_{a}$ is the corresponding rotor angle.
Curve 2 represents the power-angle relationship when circuit 2 is out of service. When one of the circuits is out of service, the effective reactance $X_{T}$ is higher. Hence, the maximum power transfer is low. In this situation, the mechanical input power is $P_{m}$, but now the rotor angle is $\delta_{b}$ corresponding to the operating point $\mathrm{b}$ on curve 2 . Here the rotor angle is higher in order to transmit the same steady state power.

The equation of motion or swing equation ca be written as

$$
\frac{2 H}{\omega_{0}} \frac{d^{2} \delta}{d t^{2}}=P_{m}-P_{\max } \sin \delta
$$

Where

$P_{m}=$ mechanical power input, in pu

$P_{\max }=$ max electrical power output, in pu

$\mathrm{H}=$ inertia constant, in MW.sec/MVA

$\delta=$ rotor angle, in electrical radians

$\mathrm{t}=$ time, in sec

\subsection{Equal-Area Criterion}

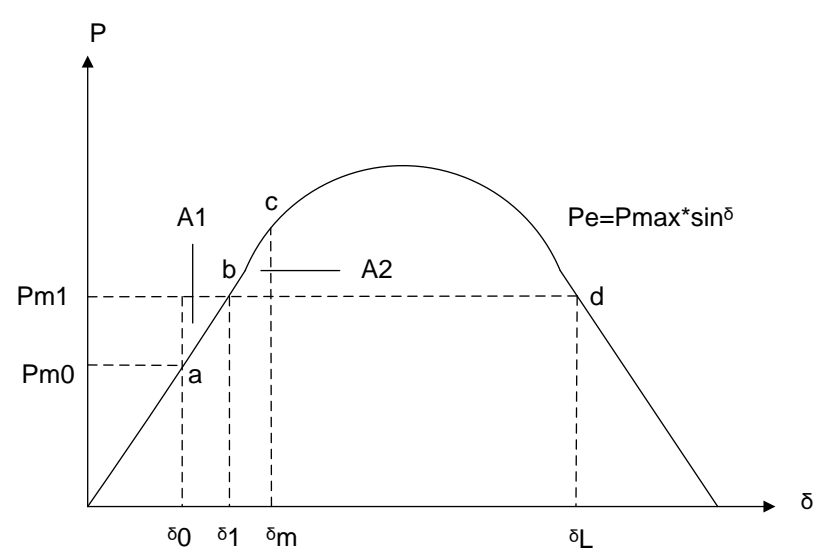

Fig 5: Power angle variation

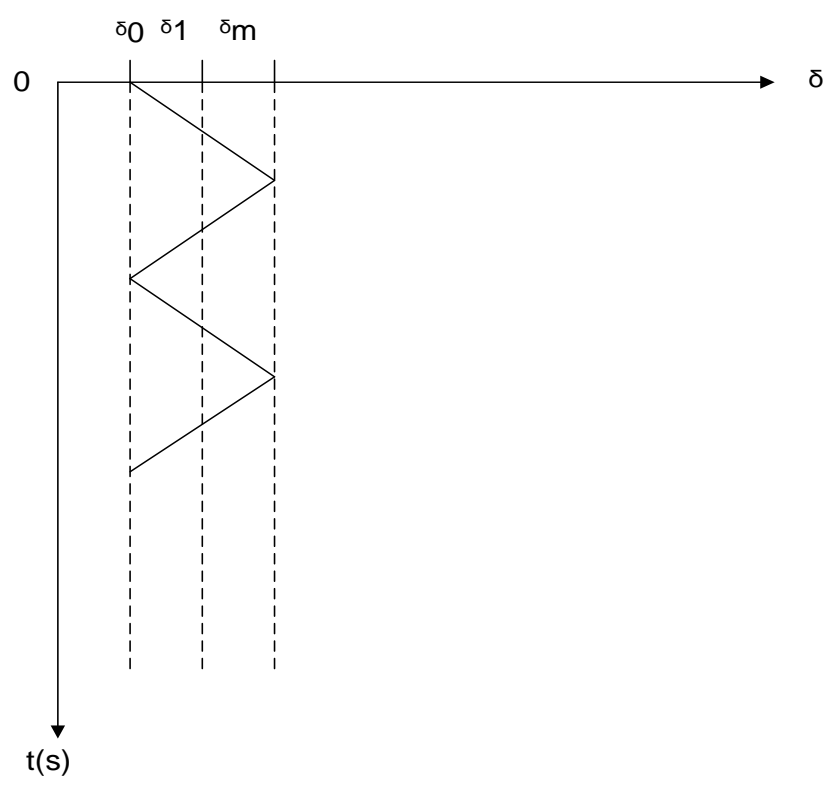

Fig 6: Rotor angle time response 
For the system shown in fig 6 it is necessary to solve the swing equation to determine whether the rotor angle remains stable or not. One of the limitations of the swing equation method is that it is not applicable to multi-machine system with detailed representation of synchronous machines.

The relation between the rotor angle and the accelerating power is

$$
\frac{d^{2} \delta}{d t^{2}}=\frac{\omega_{0}}{2 H}\left(P_{m}-P_{e}\right)
$$

Eq(4) cannot be solved directly as $P_{e}$ is a non-linear function of $\delta$. So, both sides are multiplied by $2 \frac{d \delta}{d t}$, then

$$
2 \frac{d t}{d \delta} \frac{d^{2} \delta}{d t^{2}}=\frac{\omega_{0}\left(P_{m}-P_{e}\right)}{H} \frac{d t}{d \delta}
$$

Or

$$
\frac{d t}{d \delta}\left[\frac{d \delta}{d t}\right]^{2}=\frac{\omega_{0}\left(P_{m}-P_{e}\right)}{H} \frac{d t}{d \delta}
$$

Integrating gives

$$
\left[\frac{d \delta}{d t}\right]^{2}=\int \frac{\omega_{0}\left(P_{m}-P_{e}\right)}{H} d \delta
$$

Initially the speed deviation $\frac{d \delta}{d t}$ is zero. It will change as a result of the disturbance. As shown in fig 5, for a stable operation $\delta$ deviates in a bounded region. It also needs to become zero sometime after the disturbance.

So, a criterion of stability can be defined by the following equation

$$
\int_{\delta 0}^{\delta_{m}} \frac{\omega_{0}}{H}\left(P_{m}-P_{e}\right) d \delta=0
$$

\section{Where}

$\delta_{0}=$ initial rotor angle

$\delta_{m}=$ maximum rotor angle.

Thus, it can be concluded that when area $A_{1}$ is equal to area $A_{2}$, the system is stable.

The energy gained during acceleration when $\delta$ changes from $\delta_{0}$ to $\delta_{1}$ is

$$
E_{1}=\int_{\delta_{0}}^{\delta_{1}}\left(P_{m}-P_{e}\right) d \delta=\operatorname{areaA}_{1}
$$

The energy lost during deceleration when $\delta$ changes from $\delta_{1}$ to $\delta_{m}$ is

$$
E_{2}=\int_{\delta_{1}}^{\delta_{m}}\left(P_{e}-P_{m}\right) d \delta=\operatorname{areaA}_{2}
$$

Thus the equal area criterion can be used to determine the maximum swing of $\delta$ and the stability of the system without solving the swing equation.

\subsection{Response to a Short-Circuit Fault}

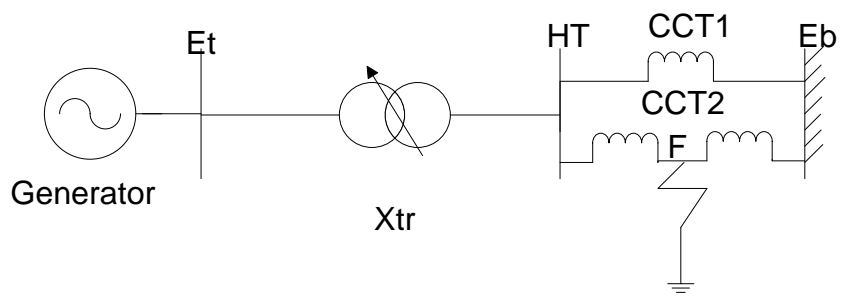

Fig 7: Single-line diagram

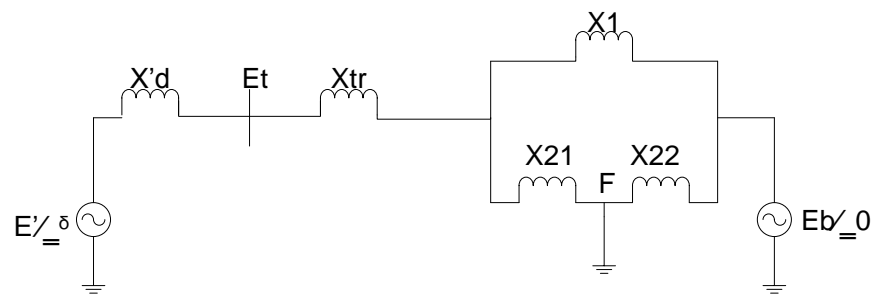

Fig 8: Equivalent circuit

Figure 7 represents a single machine infinite bus system, a three phase fault is analyzed at point F. Figure 8 represents the equivalent circuit of the single machine infinite bus system. If the fault location F is near the sending end (HT) no power is transmitted to the infinite bus. But if the fault location $\mathrm{F}$ is located some distance away from the sending end, some active power is transmitted to the infinite bus while the fault is still on.

Figure 9 and 10 show power-angle plots for three conditions: (1) pre-fault (2) a three phase fault on circuit 2 at some distance from the sending end and (3) post-fault. Figure 9 represents a stable case while figure 9 represents the unstable case. 


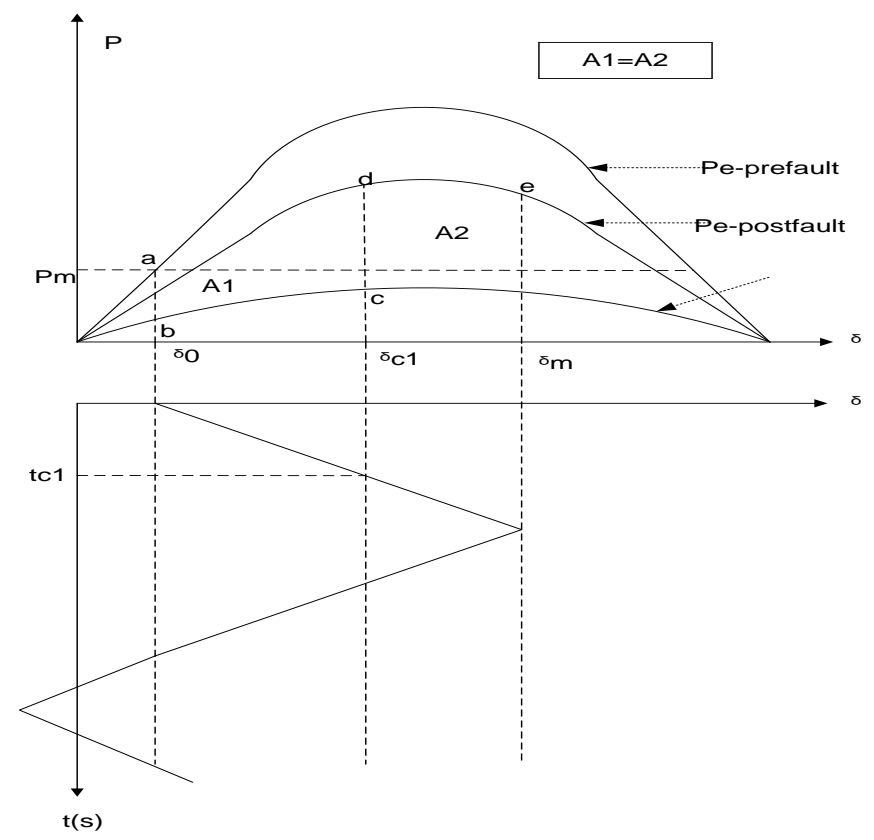

Fig 9: Response to a fault cleared in $t_{c 1}$ seconds-stable case

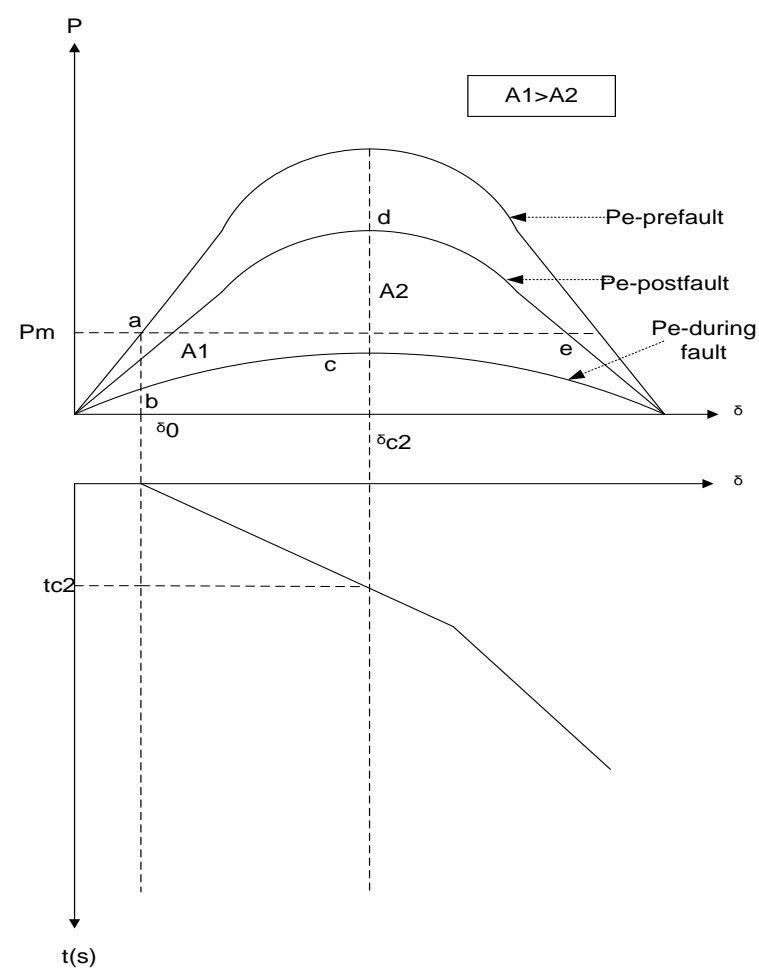

Fig 10: Response to a fault cleared in $t_{c 2}$ seconds-unstable case

\section{AUTOMATIC VOLTAGE REGULATOR AND POWER SYSTEM STABILIZER}

\subsection{Automatic Voltage Regulator}

PSAT has three different types of AVRs. AVR type I is a standard Italian regulator, AVR type II is the standard IEEE model 1 and AVR type III is the simplest model which can be used for rough stability evaluations [8].
The model used in this paper is AVR type III and shown in fig 12 . It is described by the following equations:

$$
\begin{aligned}
& \dot{v_{m}}=\left(V-v_{m}\right) / T_{r} \\
& \dot{v_{r}}=\left(\mu_{0}\left(1-\frac{T_{1}}{T_{2}}\right)\left(v_{r e f}-v_{m}\right)-v_{r}\right) / T_{2} \\
& \dot{v_{f}}=\left(\left(v_{r}+\mu \frac{T_{1}}{T_{2}}\left(v_{r e f}-v_{m}\right)+v_{f}\right) \frac{V}{V_{0}}-v_{f}\right) / T_{\varepsilon}
\end{aligned}
$$

Where

$v_{m}=$ Indexes of state variable

$T_{r}=$ Measurement time constant

$v_{r}=$ Regulator voltage

$\mu_{0}=$ Regulator gain

$T_{1}=$ Regulator zero

$T_{2}=$ Regulator pole

$v_{\text {ref }}=$ Reference voltage

$v_{f}=$ Field voltage

$v_{f} 0=$ Field voltage offset

$v_{0}=$ Bus voltage offset

$T_{\varepsilon}=$ Fixed small time constant

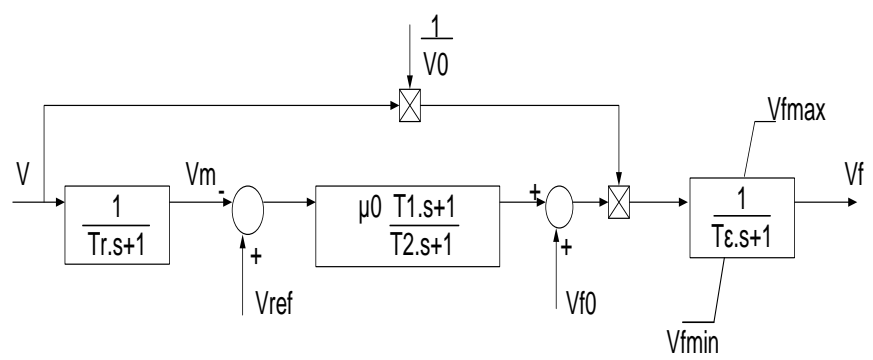

Fig 12: AVR type III

\subsection{Power System Stabilizer}

PSS are used for damping power system oscillations. PSAT provides five models of PSS [8]. The model used in this paper is type II which is shown in fig 13. It described by the following equation:

$\dot{v_{1}}=-\left(K_{w} v_{s I}+v_{1}\right) / T_{w}$

$\dot{v}_{2}=\left(\left(1-\frac{T_{1}}{T_{2}}\right)\left(K_{w} v_{S I}+v_{1}\right)-v_{2}\right) / T_{2}$

$\dot{v}_{3}=\left(\left(1-\frac{T_{3}}{T_{4}}\right)\left(v_{2}+\left(\frac{T 1}{T 2}\left(K_{w} v_{S I}+v_{1}\right)\right)\right)-v_{3}\right) / T_{4}$

$\dot{v_{S}}=\left(v_{3}+\frac{T_{3}}{T_{4}}\left(v_{2}+\frac{T 1}{T 2}\left(K_{w} v_{S I}+v_{1}\right)\right)-v_{S}\right) / T_{\varepsilon}$ 
Where

$v_{1}=$ Indexes of the state variable $v_{1}$

$v_{2}=$ Indexes of the state variable $v_{2}$

$v_{3}=$ Indexes of the state variable $v_{3}$

$v_{s}=$ Indexes of the state variable $v_{s}$

$K_{w}=$ Stabilizer gain

$T_{w}=$ Wash-out time constant

$T_{1}=$ First stabilizer time constant

$T_{2}=$ Second stabilizer time constant

$T_{3}=$ Third stabilizer time constant

$T_{4}=$ Fourth stabilizer time constant

$T_{\varepsilon}=$ Small time constant

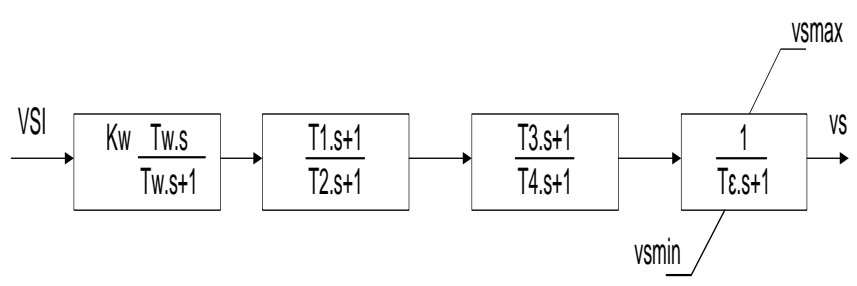

Fig 13: PSS type II

\section{TEST SYSTEM}

The test system used here is two area system. The system consists of four generators, four step-up transformers, two loads and two shunt capacitors. The data for the system has been taken from [6]. The system is shown in figure 11.

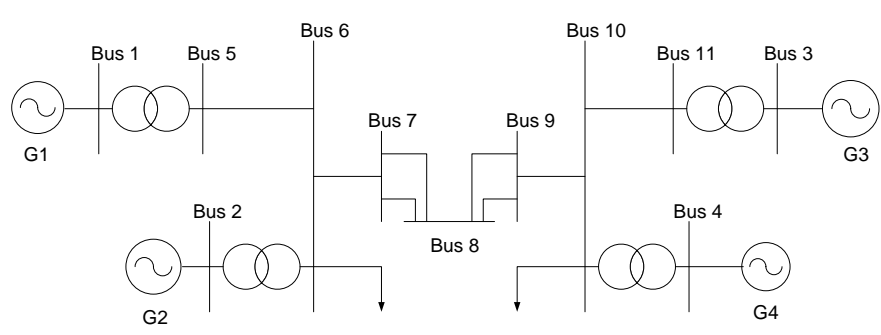

Fig 11: Two Area System

Here two cases are simulated:

Case (1) all synchronous generators are considered without the effect of AVR and PSS and

Case (2) all Synchronous generators are considered with the effect of AVR and PSS.

\section{SIMULATION RESULTS}

The simulation has been performed in MATLAB/PSAT toolbox. As discussed earlier the test system used is two area system. A three phase fault is simulated on the system. The fault is simulated at $5 \mathrm{~s}$ and the fault clearing time is $5.25 \mathrm{~s}$.

Case (1) all synchronous generators are considered without the effect of AVR and PSS

Generator 1:

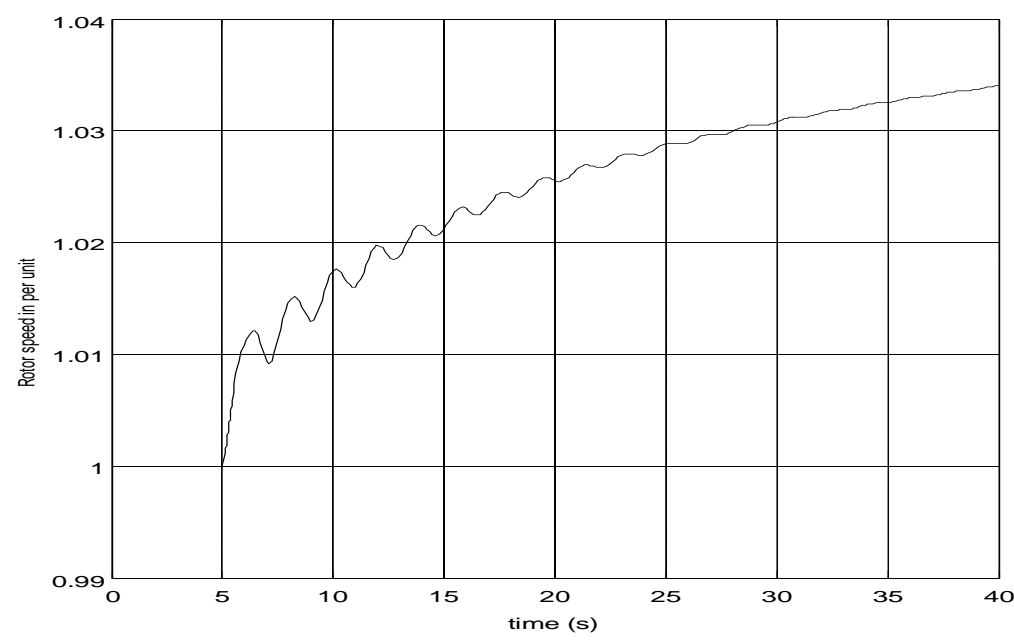


Generator 2:

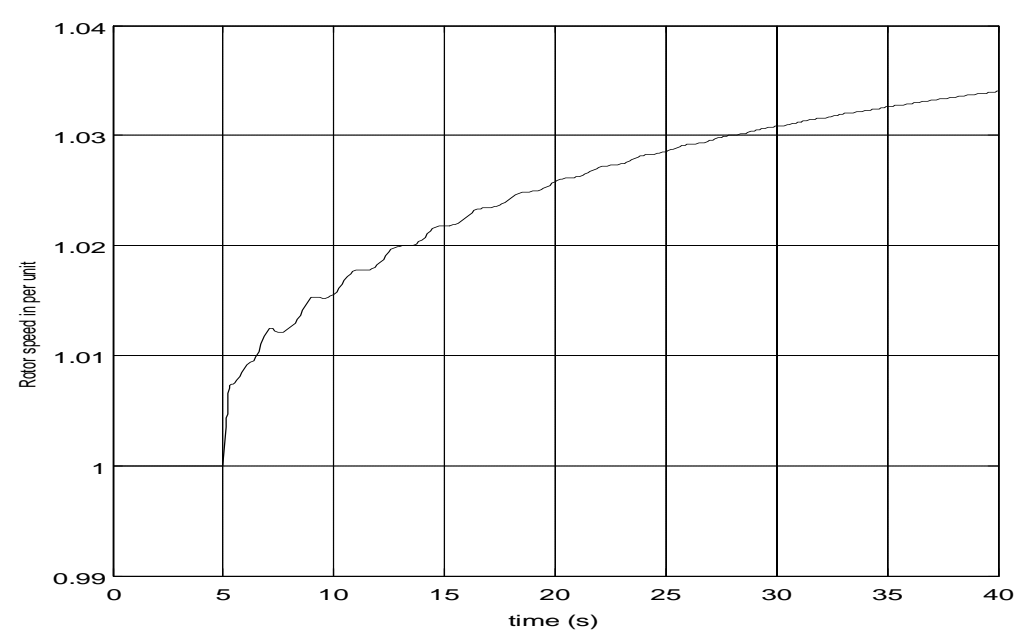

Generator 3:

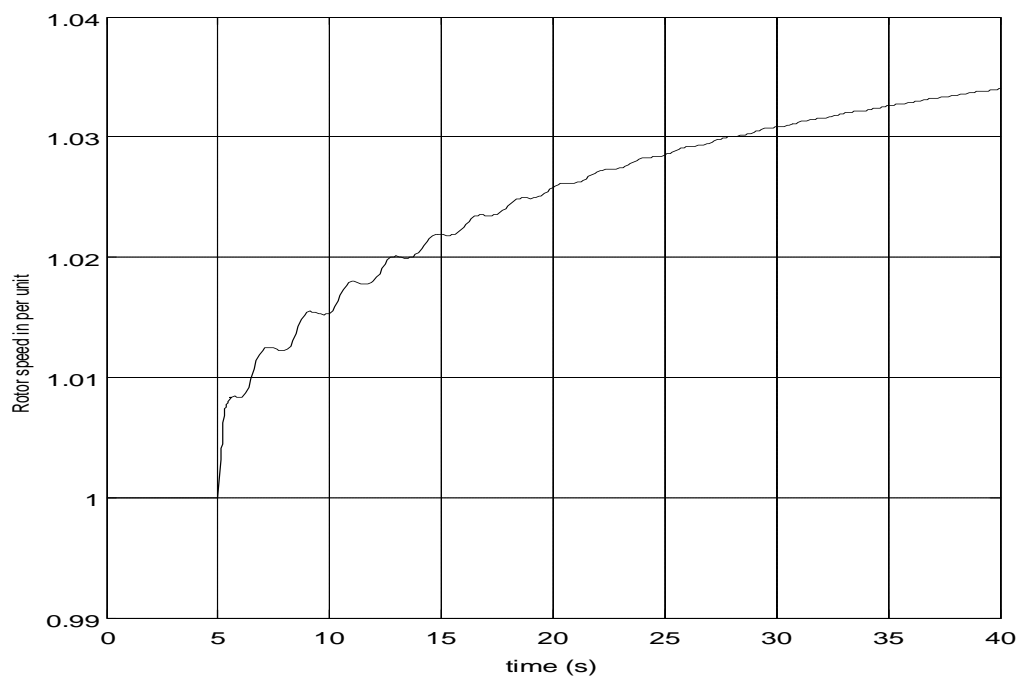

Generator 4:

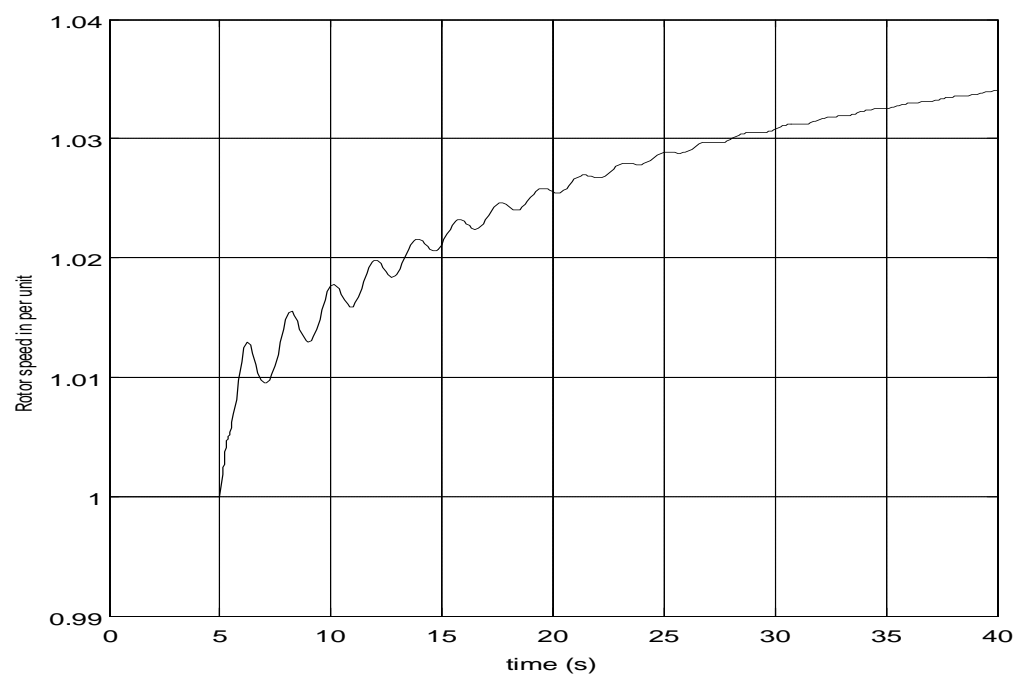

Fig 14: Rotor speed for case (1) 
Case (2) all Synchronous generators are considered with the effect of AVR and PSS

Generator 1:

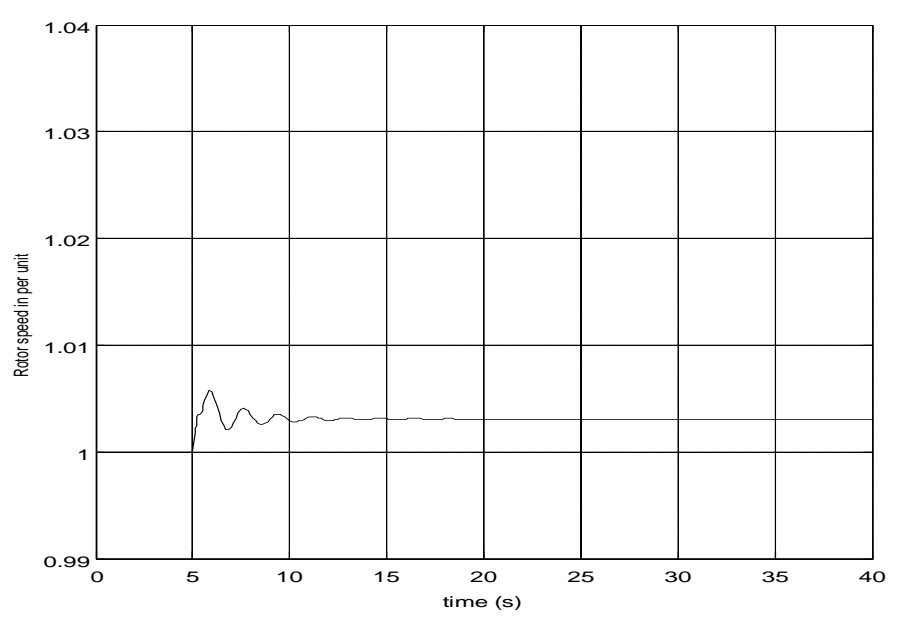

Generator 2:

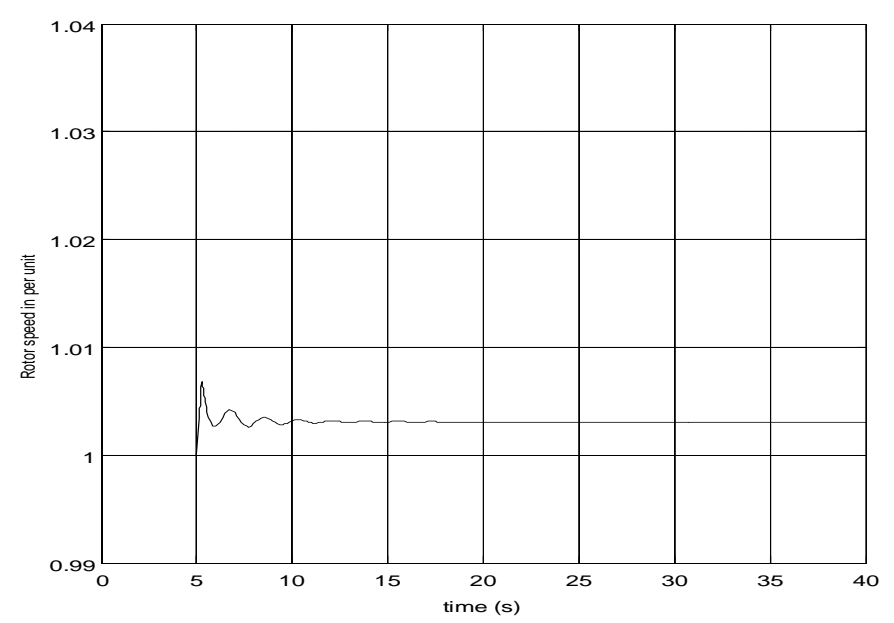

Generator 3:

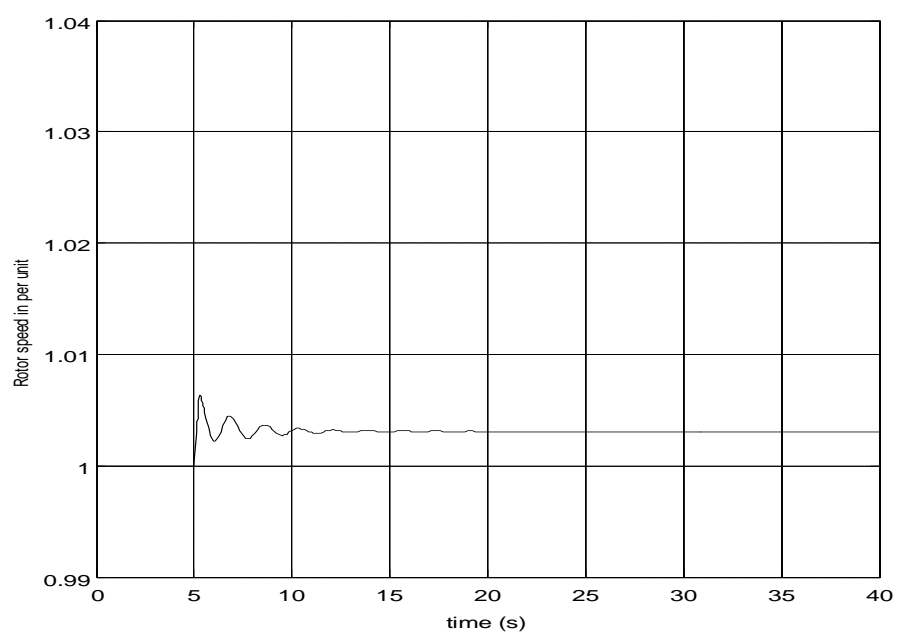


Generator 4:

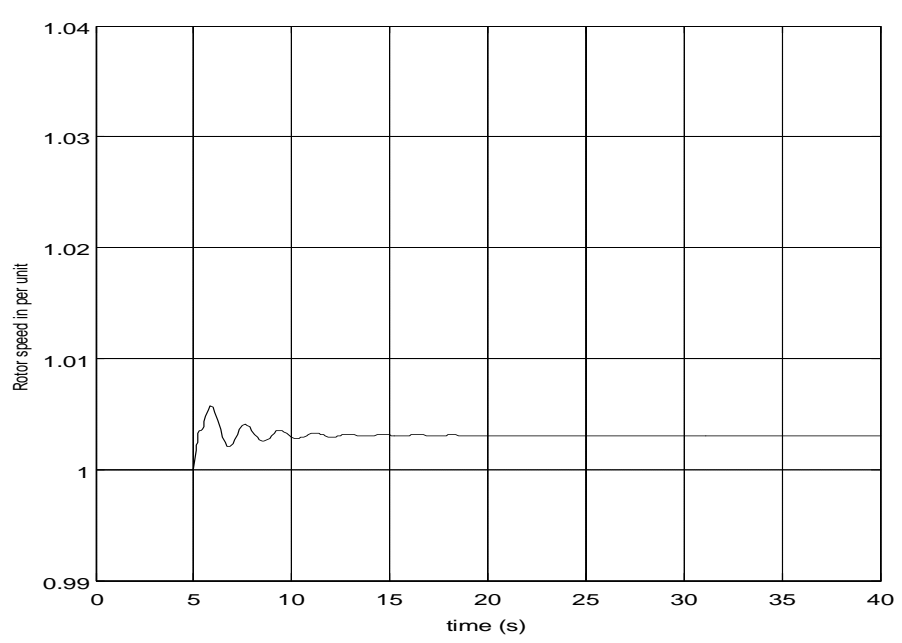

Fig 15: Rotor speed for case (2)

Case (1) all synchronous generators are considered without the effect of AVR and PSS and

Generator 2:

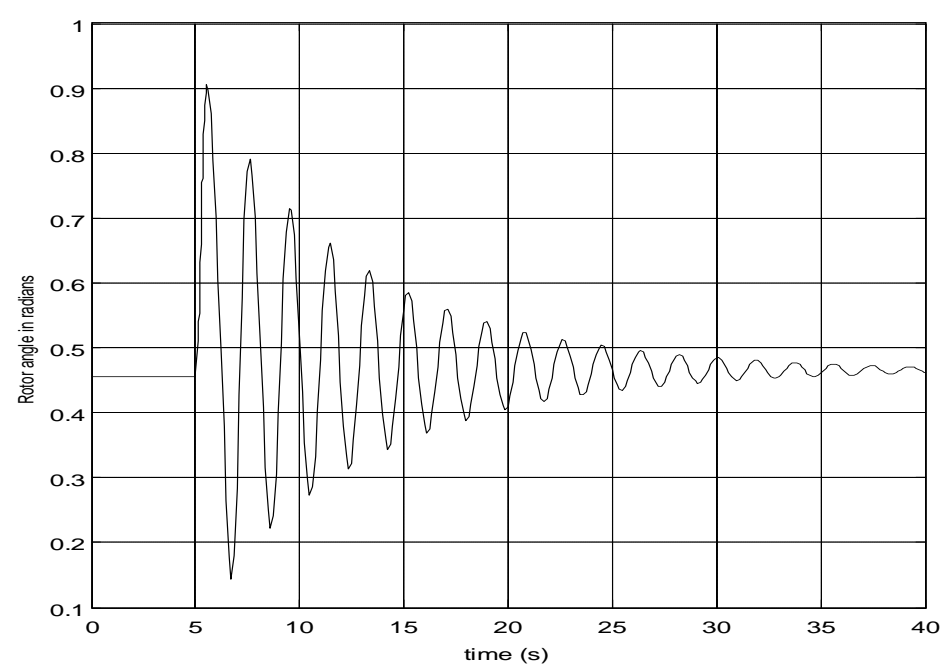

Generator 3:

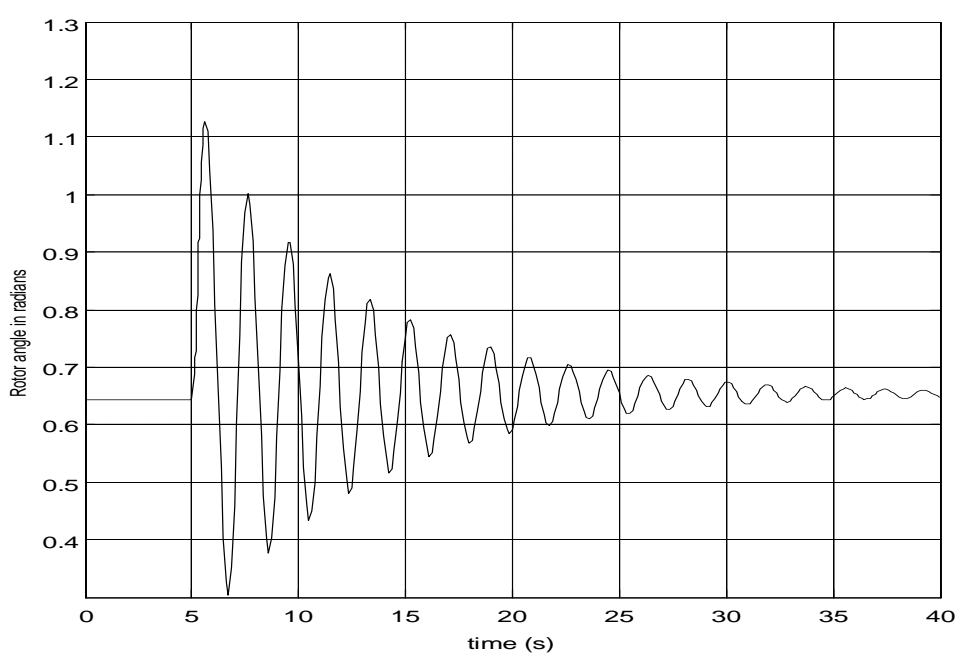


Generator 4:

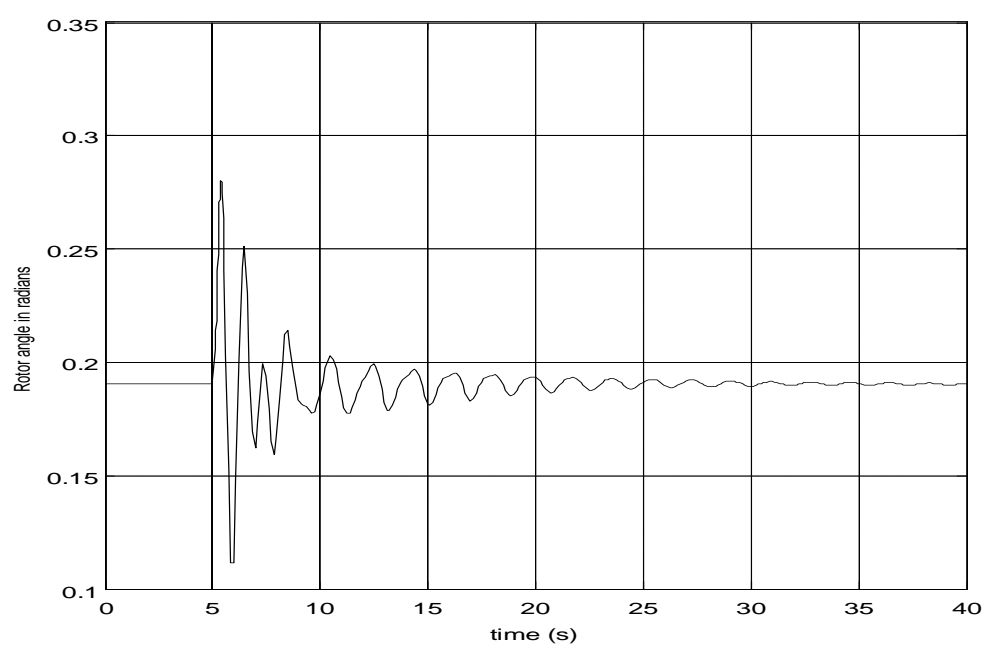

Fig 16: Rotor angle for case (1)

Case (2) all Synchronous generators are considered with the effect of AVR and PSS.

Generator 2:

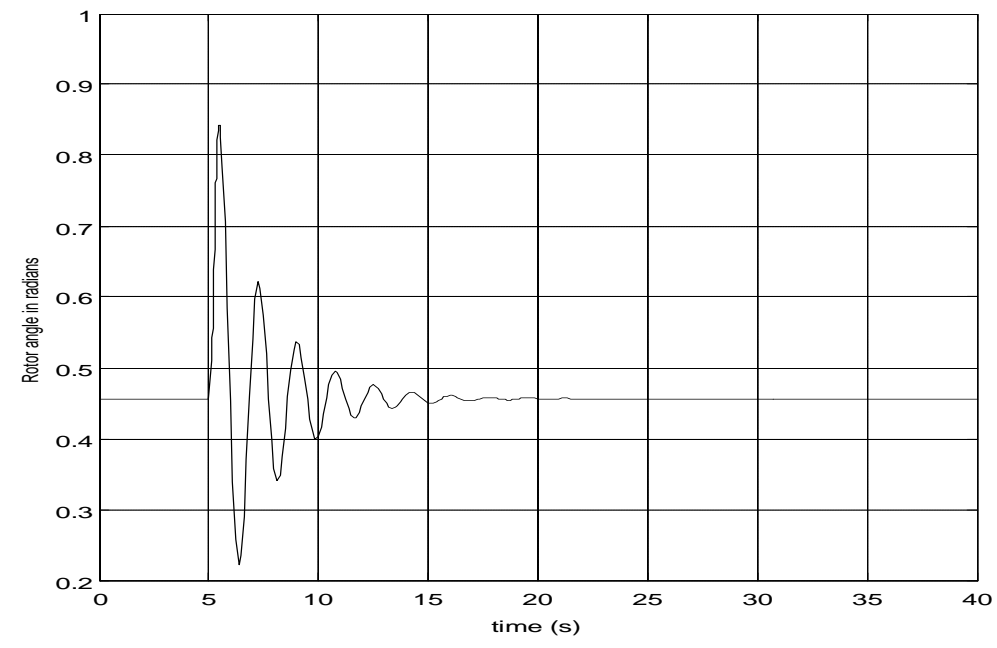

Generator 3:

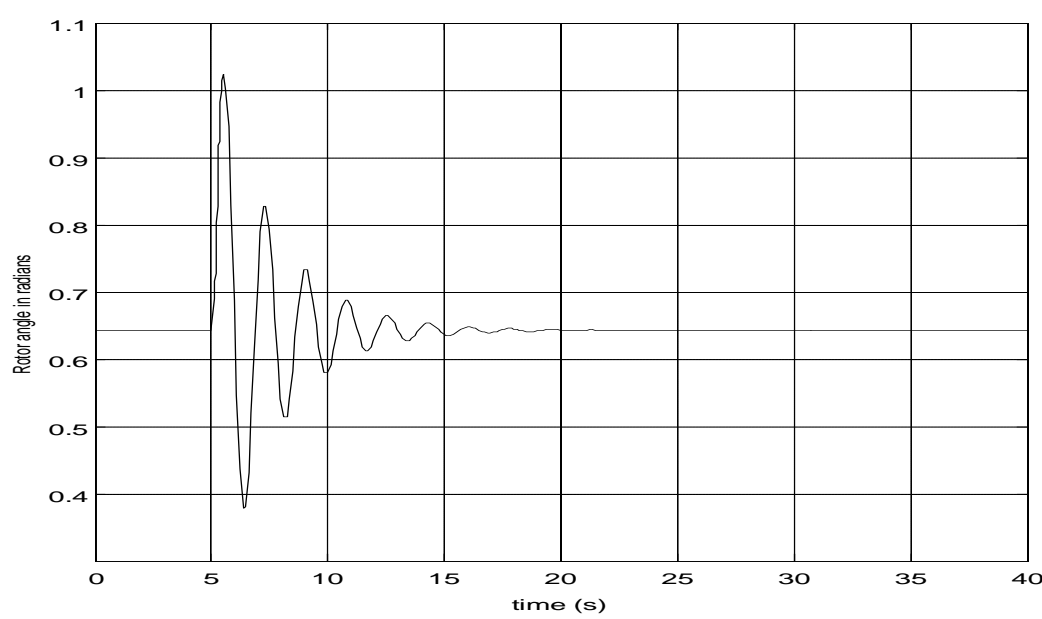


Generator 4:

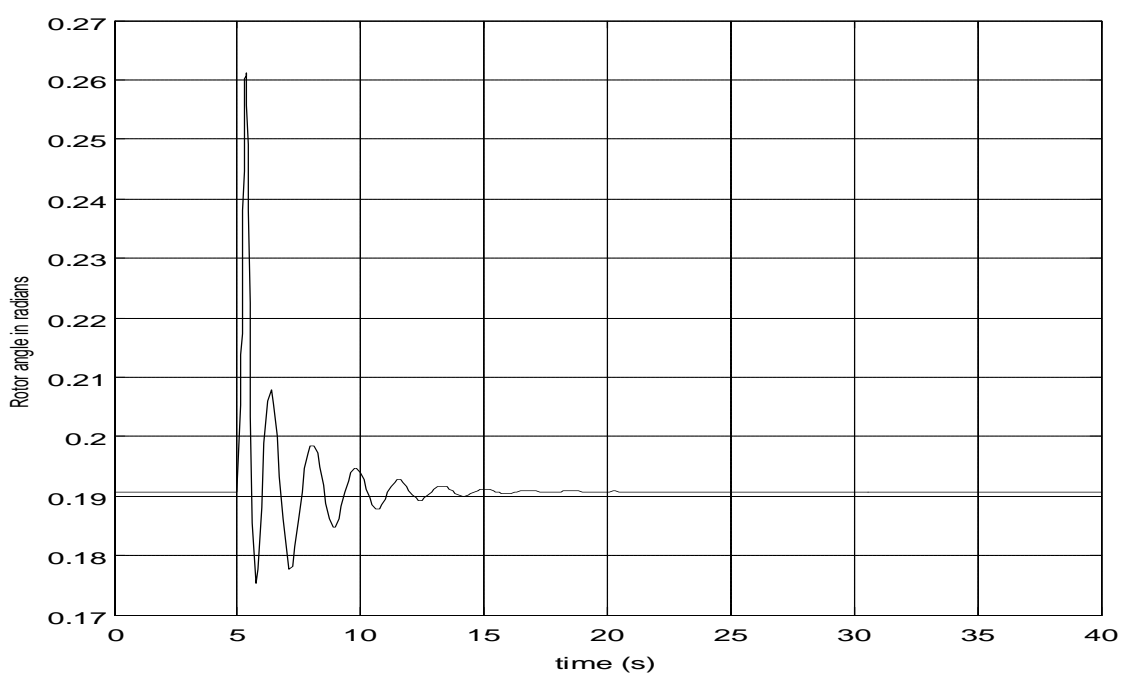

Fig 17: Rotor angle for case (2)

As seen in figure 14 and 16, the rotor speed and angle have large oscillations which makes the system unstable. Thus in order to reduce these inter-area oscillations AVR and PSS are connected to the synchronous generator which reduce the oscillations of the rotor speed and angle and make the system stable. The results of the case (2) rotor speed and angle can be seen in figure 15 and 17 .

\section{CONCLUSION}

Transient stability analysis is performed on a two area system by simulating a three phase fault on a bus in MATLAB/PSAT. From the results it can be concluded that the system becomes unstable when subjected to a three phase fault but when AVR and PSS are connected to the synchronous generator the inter-area oscillations can be damped effectively.

\section{REFERENCES}

[1] C.P.Steinmetz, ,Power control and stability of electric generating stations," AIEE Trans. Vol. XXXIX, Part II, pp. 1215-1287, July 1920.

[2] AIEE Subcommittee on Interconnection and stability factors," First report of power system stability," AIEE Trans., pp. 51-80, 1926.

[3] G.S.Vassell," Northeast blackout of 1965," IEEE Power Engineering review, pp. 4-8, Jan. 1991.

[4] P. Kundur, J. Paserba, N. Hatziargyrion, D. Hill, A. Bose, C. Canizares, V. Ajjarapu, G. Andersson, A. Stankovic, C. Taylor, T. Van Cutsem and V. Vittal, "Definition and classification of power system stability," IEEE Trans. on Power Systems, Vol. 19, No. 2, May 2004.

[5] Task Force on Terms and Definitions, System Dynamic Performance Subcommittee and Power system Engineering Committee," Proposed Terms and Definitions for Power System Stability," IEEE
Trans. on Power Apparatus and Systems, Vol. PAS101, No. 7, July 1982.

[6] P. Kundur," Power System Stability and Control," New York, Mc-Graw-Hill, 1994.

[7] K. R. Padiyar," Power System Dynamics, Stability and Control," BS Publications, Second edition, 2008.

[8] Milano Federico. Power system analysis toolbox. PSAT version 2.1.6.

[9] B. Mehta, P. Bhatt, V. Pandya," Small Signal Stability analysis of Power Systems with DFIG based wind power penetration," Electrical Power and Energy Systems, Jan. 2014. 